\title{
Donor selection for ex vivo-expanded natural killer cells as adoptive cancer immunotherapy
}
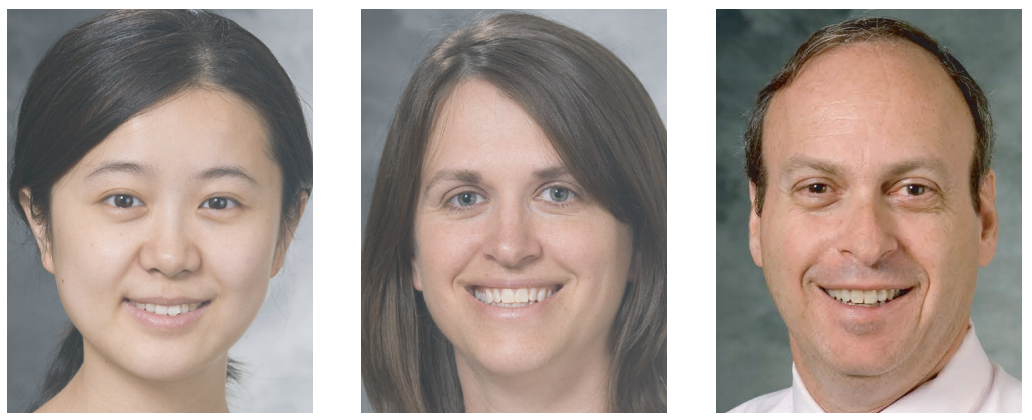

Wei Wang1', Amy K Erbe', Kenneth B DeSantes ${ }^{2} \&$ Paul M Sondel $^{* 1,2}$

First draft submitted: 24 January 2017; Accepted for publication: 15 February 2017; Published online: 11 May 2017

Natural killer (NK) cells are a mainstay of innate immunity and are involved in several strategies of cancer immunotherapy [1]. Expressed on NK cells, killer immunoglobulin-like receptors (KIRs) can influence NK cell function via interactions with their corresponding KIR-ligands (certain MHC class I molecules) [2]. When inhibitory KIRs on mature NK cells recognize their cognate ligand, an inhibitory signal results, attenuating NK cell function (i.e., cytotoxicity and cytokine release) [3]. In contrast, when inhibitory KIRs on developing NK cells recognize their cognate ligand, augmented differentiation of the NK cell results, conferring greater capability for NK cell function, unless they subsequently encounter that same KIR-ligand; this process is termed 'licensing' [4]. KIRs and KIR-ligands are each polymorphic, and inherited independently on chromosomes 19 and 6, respectively. For this reason, cancer immunotherapies that may depend on the antitumor capability of NK cells from allogeneic donors, such as, allogeneic hematopoietic stem cell transplant (HSCT) [5], or infusions of fresh NK cells [6] or ex vivo activatedexpanded NK (AE-NK) cells [7], may be influenced by the KIR/KIR-ligands of the donor and of the cancer patient (recipient). A number of approaches have been utilized to select potentially superior HSCT or NK cell donors for cancer patients, using genotype information for KIR and/ or KIR ligands of the donor or recipient. This paper summarizes these selection models and proposes a new approach that synthesizes concepts from some of these former algorithms, based on recent data from our lab [8].

Currently, there are four different donor selection models (lines 1-4 in Table 1) being utilized for selection of HSCT or NK cell donors based on donor and recipient KIR and/or KIR-ligand genotypes. The first is the ligand-ligand mismatch model (line 1 in Table 1), proposed by Ruggeri et al. [5]. It is based on KIR-ligand genotypes of the donor and the recipient; it does not consider KIR genes in either the donor or the recipient.

\section{KEYWORDS}

- adoptive transfer $\bullet$ donor selection - ex vivo expansion

- immunotherapy $\bullet \mathrm{KIR} \bullet \mathrm{KIR}$-ligands - NK cells

"Based on previously published models for donor selection and our initial in vitro data with ex vivo-expanded natural killer (NK) cells, we suggest that the licensed receptor-ligand mismatch model proposed here may predict better activatedexpanded NK cell donors for recipients being considered for activated-expanded NK cell adoptive immunotherapy." 
Table 1. Five models based on killer immunoglobulin-like receptors and killer immunoglobulin-like receptor ligand genotyping for donor selection in stem cell transplantation or adoptive natural killer cell transfer for cancer patients.

\begin{tabular}{|c|c|c|c|c|}
\hline Models & Definition & Advantage & Disadvantage & Ref. \\
\hline $\begin{array}{l}\text { Ligand-ligand } \\
\text { mismatch }\end{array}$ & $\begin{array}{l}\text { The donor has at least one KIR- } \\
\text { ligand that is missing in the } \\
\text { recipient }\end{array}$ & $\begin{array}{l}\text { Only requires genotyping of KIR- } \\
\text { ligands }\end{array}$ & $\begin{array}{l}\text { Does not consider the KIR receptors in } \\
\text { donors, which are important for donor } \\
\text { NK cell function } \\
\text { Considers only inhibitory KIR genes }\end{array}$ & [5] \\
\hline $\begin{array}{l}\text { Receptor- } \\
\text { receptor } \\
\text { mismatch }\end{array}$ & $\begin{array}{l}\text { The donor has at least one } \\
\text { KIR gene that is missing in the } \\
\text { recipient }\end{array}$ & $\begin{array}{l}\text { Only requires genotyping of KIR } \\
\text { receptors }\end{array}$ & $\begin{array}{l}\text { Does not consider KIR-ligand in recipients } \\
\text { that are important for donor NK cell } \\
\text { inhibition following transplant }\end{array}$ & [9] \\
\hline $\begin{array}{l}\text { Haplotype-B } \\
\text { score }\end{array}$ & $\begin{array}{l}\text { The donor has higher } \\
\text { haplotype-B score }\end{array}$ & $\begin{array}{l}\text { Takes into consideration all KIR genes, } \\
\text { including activating KIR genes with } \\
\text { unknown ligands }\end{array}$ & $\begin{array}{l}\text { Does not consider any KIR or KIR-ligand } \\
\text { genes in the recipient, which may be } \\
\text { important for modulating donor NK cell } \\
\text { function in the recipient }\end{array}$ & [11] \\
\hline
\end{tabular}

This ligand-ligand mismatch model proposes that having any KIR-ligand genes missing in the recipient that are present in the donor will result in more active antirecipient (i.e., antileukemic) NK cell clones and better outcomes, compared with a recipient that is not missing any KIR-ligands present in the donor. Using this model to evaluate clinical results of HSCT for acute myeloid leukemia, the recipients of ligand-ligand mismatched donors showed less probability of relapse over the recipients of ligand-ligand matched donors [5].

The second model, the receptor-receptor mismatch model, is based on the status of the KIR genes of the donor and the recipient, without consideration of KIR-ligand genotypes (line 2 in Table 1). This model proposes that better NK cell function will occur when the recipient is missing any KIR gene (either activating or inhibitory) that is present in the donor [9].

The third model, the receptor-ligand mismatch model, was proposed by Leung et al. [10] . This model takes into consideration the inhibitory KIR of the donor as well as the KIR-ligand genotype of the recipient (line 3 in Table 1). The receptor-ligand mismatch model proposes that having at least one inhibitory KIR gene expressed by the donor's NK cells with the corresponding KIR-ligand absent in the recipient ('ligand-missing' status), predicts more active donor-derived antirecipient NK cell clones than if the recipient is not missing any KIR-ligands for the donor's KIRs ('ligands-present' status). Using this model for patients with lymphoid malignancy receiving allogeneic HSCT, ligand-missing recipients had less risk of relapse compared with ligands-present recipients [10].

The fourth model, like the second model is based solely on the analyses of KIR genes, without attention to KIR-ligands (line 4 in Table 1). However, this model focuses only on the KIR genes of the donor, with an emphasis on the presence of activating KIRs, which are more frequent in KIR B haplotypes [11]. Unrelated donor HSCT for acute myeloid leukemia results in better outcomes when utilizing donors with higher haplotype-B scores [11].

These models have been investigated and discussed primarily in the setting of allogeneic HSCT. Although each has shown correlations with outcome, the clinical settings in which they have been applied have not always been comparable, and inconsistent results have been observed in studies with different cohorts of patients $[5,10,12,13]$. Thus, there is currently not a standard criterion used for donor selection to maximize NK cell mediated tumor cytotoxicity.

The interaction between KIR and KIRligand may also play a role in the immunotherapeutic function and efficacy of adoptively transferred NK cells. Although freshly isolated allogeneic NK cells have been utilized in clinical trials [14-16], cell numbers are 
limited; ex vivo AE-NK cells enable administration of $>100$-fold more NK cells, with augmented in vitro functions [17]. Thus, we have recently investigated the activity of AE-NK cells in vitro, using a clinically relevant activation-expansion methodology. We found that AE-NK cell function was still influenced by $\mathrm{KIR} / \mathrm{KIR}$-ligand interactions and that prior in vivo licensing still modulated $\mathrm{AE}-\mathrm{NK}$ cell behavior [8].

We cultured donor peripheral blood mononuclear cells (PBMCs) from KIR/KIR-ligand genotyped healthy donors with a feeder cell line, K562-mbIL15-41BBL, in the presence of IL-2 [17], to generate a large number of AE-NK cells with high purity [8]. We then tested these AE-NK cells for their interaction with target cells devoid of classical class I HLA (the HLAnull 721.221 Epstein-Barr virus transformed B lymphoblastoid cell line) or variants of these same 721.221 cells transfected to express individual KIR-ligand ( $H L A-C 1, H L A-C 2$ or $H L A-B w 4)$. We found that these AE-NK cells were more potently reactive to 721.221 cells that were missing KIR-ligands corresponding to the KIRs of the AE-NK cells [8]. This result is analogous to the enhanced NK cell function for 'ligand-missing' donor-recipient pairs based on the receptor-ligand mismatch model (line 3 in Table 1). In addition, we found that the KIR-ligand (HLA-C1,HLA-C2 and/ or $H L A-B w 4)$ genotype of the donor could influence the function of these AE-NK cells. Specifically, AE-NK cells were more potent when they were licensed, namely when they expressed a specific KIR that corresponded to a KIR-ligand from that same AE-NK donor [8]. This observation is consistent with the prior in vivo process of NK cell 'licensing', and relates somewhat to the predictions based on the ligand-ligand mismatch model (line 1 in Table 1).

Based on these in vitro findings [8], we hypothesize that the use of AE-NK cells for adoptive transfer could benefit from a model that would combine both the ligand-ligand mismatch and the receptor-ligand mismatch models. We have designated this as the 'licensed receptor-ligand mismatch' model (line 5 in Table 1). Specifically, we hypothesize that improved NK cell alloreactivity would result if the AE-NK cell donor has a licensed KIR gene (namely the coinheritance of both in a given KIR gene and the gene for its corresponding ligand), provided the same corresponding KIR-ligand is missing in the recipient. Under these conditions, the donor's AE-NK cell repertoire contains a subset of $\mathrm{NK}$ cells that are more activated (due to their licensed status) and would not be inhibited, due to the recipient's missing ligand.

We have thus considered the likelihood of finding such a donor, either among HLA haploidentical family members or randomly selected unrelated potential AE-NK donors (Table 2). For this analysis, we focused on the four main inhibitory KIRs, for which ligands have been identified: KIR2DL1/HLA-C2, KIR2DL2/HLA-C1, KIR2DL3/HLA-C1 and

Table 2. The frequency of HLA genotypes in patients and the probability of ideal donor genotypes in unrelated and HLA-haploidentical donors.

\begin{tabular}{|c|c|c|c|c|c|c|c|c|c|}
\hline \multirow{2}{*}{$\begin{array}{l}\text { Frequency in } \\
\text { population } \\
(\%)^{\dagger}\end{array}$} & \multicolumn{3}{|c|}{$\begin{array}{l}\text { Recipient HLA } \\
\text { genotype }\end{array}$} & \multirow[t]{2}{*}{ Ideal donor genotype } & \multirow{2}{*}{$\begin{array}{l}\text { Frequency } \\
\text { in unrelated } \\
\text { donor }(\%)^{\S}\end{array}$} & \multirow{2}{*}{$\begin{array}{l}\text { No. of unrelated } \\
\text { donors to } \\
\text { screen" }\end{array}$} & \multirow{2}{*}{$\begin{array}{l}\text { Frequency in } \\
\text { one haplo- } \\
\text { donor }(\%)^{\S}\end{array}$} & \multirow{2}{*}{$\begin{array}{l}\text { Frequency in } \\
\text { two haplo- } \\
\text { donors (\%) }\end{array}$} & \multirow{2}{*}{$\begin{array}{l}\text { No of } \\
\text { haplo-donors } \\
\text { to screen" }\end{array}$} \\
\hline & $C 1$ & $\mathrm{C} 2$ & $B w 4^{*}$ & & & & & & \\
\hline 31 & + & + & + & & & & & & \\
\hline 12 & + & + & - & $B w 4+, 3 D L 1+$ & 59 & 8 & 36 & 60 & 16 \\
\hline 14 & + & - & + & $C 2+, 2 D L 1+$ & 61 & 8 & 39 & 63 & 14 \\
\hline 22 & + & - & - & $B w 4+, 3 D L 1+$ or $C 2,2 D L 1+$ & 84 & 4 & 61 & 85 & 8 \\
\hline 17 & - & + & + & $\mathrm{C} 1+$ & 79 & 5 & 60 & 84 & 8 \\
\hline 4 & - & + & - & $C 1+$ or $B w 4+, 3 D L 1+$ & 91 & 3 & 75 & 94 & 6 \\
\hline \multicolumn{10}{|c|}{$\begin{array}{l}\text { This table only considers the gene frequency of } H L A-B-B w 4 \text {, excluding } H L A-A-B w 4 \text { genotype, for the calculation of } B-B w 4 \text { and } B-B w 6 \text { allele freqeuncies. } \\
\text { sprobability that a single randomly selected unrelated donor, or a single haploidentical parent will be an ideal donor; this calculation uses the genotype and allele frequency in } \\
\text { patients that were genotyped in ECOG } 4402 \text { study; allele frequency used for calculation: } B w 4(0.38), B w 6(0.62), C 1(0.6), C 2(0.4) ; \text { genotype frequency used for calculation: } 3 D L 1+(0.96) \text {, } \\
2 D L 1+(0.98) \text {. }\end{array}$} \\
\hline
\end{tabular}


“This licensed receptorligand mismatch model requires clinical validation

before it is utilized for donor selection."
KIR3DL1/HLA-Bw4. Unfortunately, for recipients that have all three KIR-ligands present, it is impossible to find a donor that would fit this model (line 5 in Table 1) or the other two models involving ligand-missing in the recipient (lines 1 and 3 in Table 1). Based on the KIR/KIR-ligand genotypes we have analyzed 213 follicular lymphoma patients enrolled in a Phase III clinical trial (ECOG4402) [18,19]. We found the genotype of all three ligands present constituted $31 \%$ of this patient population (line 1 in Table 2). For such patients, other criteria will need to be utilized for donor selection. For the $69 \%$ of patients who are missing at least one KIR-ligand (lines 2-6 in Table 2), the likelihood of finding an ideal donor based on the licensed receptor-ligand mismatch model (line 5 in Table 1) is high. Based on the frequency of different KIR and KIR-ligand genotypes in this ECOG4402 study population, the probability of finding a donor with the ideal genotype for each of the possible recipient KIR-ligand genotypes is calculated in Table 2. For example, for the $12 \%$ of the population that have $H L A-C 1$ and $H L A-C 2$ but are missing $H L A-B w 4$ (line 2 in Table 2), a single haploidentical parent would have a $36 \%$ likelihood of fitting the ideal donor genotype using the licensed receptor-ligand mismatch model. There would be a $60 \%$ likelihood that at least one of two haploidentical parents would be such a donor. If 16 haploidentical relatives were available for screening, there would be a 99.9\% likelihood that at least 1 would be such donor. Similarly, for this same recipient, a randomly selected unrelated donor would have a $59 \%$ chance of being an ideal donor, and eight unrelated donors would need to be screened in order to identify at least one ideal donor (with $99.9 \%$ likelihood). Similar calculations for haploidentical and unrelated donors are shown for the other possible KIR-ligand genotypes (lines 3-6 in Table 2). Thus, this combined approach toward donor selection could be clinically actionable for the majority of patients missing at least one of the $H L A-C 1,-C 2$ or - Bw4 KIR-ligands. Its use in clinical decision making would require validation in analyses of HSCT or NK cell adoptive therapy clinical trials. Note that all five of these models (Table 1) focus on NK cell considerations and are based solely on KIR/KIR-ligand genotypes.

Given its potent antitumor activity, low likelihood of inducing graft versus host disease and potential for combining with other treatments, activated-expanded natural killer (AE-NK) cell adoptive transfer is a promising therapy for further testing in cancer immunotherapy [20]. Donor selection for enhanced NK cell function based on killer immunoglobulin-like receptor/ killer immunoglobulin-like receptor ligand genotype has been intensively studied in clinical settings of hematopoietic stem cell transplant. Whether the same criteria are applicable to adoptive transfer of ex vivo-expanded NK cells still needs further investigation and clarification, due to the extensive manipulation of these AE-NK cells in vitro compared with NK cells reconstituted from a stem cell transplant in vivo. Based on previously published models for donor selection and our initial in vitro data with ex vivo-expanded NK cells [5,8-11], we suggest that the licensed receptor-ligand mismatch model proposed here may predict better AE-NK cell donors for recipients being considered for AE-NK cell adoptive immunotherapy. This licensed receptor-ligand mismatch model requires clinical validation before it is utilized for donor selection.

\section{Acknowledgements}

The authors thank Lakeesha Carmichael M.S. for statistical consultation and Brad Kahl MD and Fangxin Hong PhD for access to the HIPAA-blinded DNA from the ECOG4402 population for KIR genotyping.

Financial \& competing interests disclosure PM Sondel receives NIH funding (CA014520, CA021115, CA023328, CA066636, CA180820, CA180794, CA021076, CA180799, CA14958, CA180816, CA166105 and CA197078), a Stand Up To Cancer - St. Baldrick's Pediatric Dream Team Translational Research Grant (SU2C-AACR-DT1113), and funding from the HyundaiHope on Wheels Grant, Midwest Athletes Against Childhood and University of Wisconsin-Madison Carbone Cancer Center. The authors have no other relevant affiliations or financial involvement with any organization or entity with a financial interest in or financial conflict with the subject matter or materials discussed in the manuscript apart from those disclosed.

No writing assistance was utilized in the production of this manuscript.

\section{Open access}

This work is licensed under the AttributionNonCommercial-NoDerivatives 4.0 Unported License. To view a copy of this license, visit http://creativecommons.org/ licenses/by-nc-nd/4.0/ 


\section{References}

1 Cheng M, Chen Y, Xiao W, Sun R, Tian Z. NK cell-based immunotherapy for malignant diseases. Cell. Mol. Immunol. 10(3), 230-252 (2013).

2 Lanier LL. NK Cell recognition. Annu. Rev. Immunol. 23(1), 225-274 (2005).

3 Lanier LL. Up on the tightrope: natural killer cell activation and inhibition. Nat. Immunol. 9(5), 495-502 (2008).

4 Kim S, Poursine-Laurent J, Truscott SM et al. Licensing of natural killer cells by host major histocompatibility complex class I molecules. Nature 436(7051), 709-713 (2005).

5 Ruggeri L, Capanni M, Urbani E et al. Effectiveness of donor natural killer cell alloreactivity in mismatched hematopoietic transplants. Science 295(5562), 2097-2100 (2002).

6 Curti A, Ruggeri L, D'addio A et al. Successful transfer of alloreactive haploidentical KIR ligand-mismatched natural killer cells after infusion in elderly high risk acute myeloid leukemia patients. Blood 118(12), 3273-3279 (2011).

7 Barkholt L, Alici E, Conrad R et al. Safety analysis of ex vivo-expanded NK and NK-like T cells administered to cancer patients: a Phase I clinical study. Immunotherapy 1(5), 753-764 (2009).

8 Wang W, Erbe AK, Alderson KA et al. Human NK cells maintain licensing status and are subject to killer immunoglobulinlike receptor (KIR) and KIR-ligand inhibition following ex vivo expansion. Cancer Immunol. Immunother. 65(9), 1047-1059 (2016).

9 Gagne K, Brizard G, Gueglio B et al. Relevance of KIR gene polymorphisms in bone marrow transplantation outcome. Hum. Immunol. 63(4), 271-280 (2002).

10 Leung $\mathrm{W}$, Iyengar $\mathrm{R}$, Turner $\mathrm{V}$ et al. Determinants of antileukemia effects of allogeneic NK cells. J. Immunol. 172(1), 644-650 (2004).

11 Cooley S, Trachtenberg E, Bergemann TL et al. Donors with group B KIR haplotypes improve relapse-free survival after unrelated hematopoietic cell transplantation for acute myelogenous leukemia. Blood 113(3), 726-732 (2008).

12 Davies SM, Ruggieri L, Defor T et al. Evaluation of KIR ligand incompatibility in mismatched unrelated donor hematopoietic transplants. Killer immunoglobulin-like receptor. Blood 100 (10), 3825-3827 (2002).

13 Hsu KC, Keever-Taylor CA, Wilton A et al. Improved outcome in HLA-identical sibling hematopoietic stem-cell transplantation for acute myelogenous leukemia predicted by KIR and HLA genotypes. Blood 105(12), 4878-4884 (2005).

14 Brehm C, Huenecke S, Quaiser A et al. IL-2 stimulated but not unstimulated NK cells induce selective disappearance of peripheral blood cells: concomitant results to a Phase I/ II study. PLoS ONE 6(11), e27351 (2011).

15 Geller MA, Cooley S, Judson PL et al. A Phase II study of allogeneic natural killer cell therapy to treat patients with recurrent ovarian and breast cancer. Cytotherapy 13(1), 98-107 (2011).

16 Koehl U, Sorensen J, Esser R et al. IL-2 activated NK cell immunotherapy of three children after haploidentical stem cell transplantation. Blood Cells Mol. Dis. 33(3), 261-266 (2004).

17 Fujisaki H, Kakuda H, Shimasaki N et al. Expansion of highly cytotoxic human natural killer cells for cancer cell therapy. Cancer Res. 69(9), 4010-4017 (2009).

18 Erbe AK, Wang W, Grzywacz B et al. Rituximab response in follicular lymphoma: contributions from KIR 2DS1 and HLA-C. J. Immunother. Cancer 1, 243 (2013).

19 Kahl BS, Hong F, Williams ME et al. Rituximab extended schedule or re-treatment trial for low-tumor burden follicular lymphoma: Eastern Cooperative Oncology Group Protocol E4402. J. Clin. Oncol. 32(28), 3096-3102 (2014).

20 Lee DA, Cooper L, Shpall EJ. NK cell immunotherapy for AML. Targeted Ther. Acute Myeloid Leuk. 737-755 (2013). 